\title{
Treating Low Asphaltene Asphalt using Additives
}

\author{
Ahmed Mohamady Abdalla \\ Associate Professor, \\ Construction Engineering and Utilities Department, \\ Zagazig University, Egypt
}

\begin{abstract}
Amria Refinery Company; Egypt produces asphalt of penetration values reach to about 95 units. The chemical analysis of this asphalt shows that this product has low percent of asphaltenes. The percent of asphaltenes is considered the main indictor of binding ability of any grade of asphalt and its decreasing will lead directly to increasing the softening degree of asphalt and decreasing its binding characteristics. The field experience shows that using of this asphalt type in hot paving will result low stability asphalt mixes and lead to many problems in the resulted pavement. So, it is considered low quality asphalt. This study aims to investigate the using of Silica Fume (SF), Nano Silica (NS), and hydrated lime additives in enhancing the percent of asphaltenes in Amria Asphalt and defining the minimum percentages of these additives achieving the characteristics of 60-70 asphalt penetration grade. An extensive experimental program was designed and carried out to achieve the study objective. Chemical analysis tests as well as penetration tests are used to evaluate the improvements occurred in Amria asphalt characteristics resulted from using additives as improvers. Analyzing study results, shows that considerable improvements in low quality asphalt is resulted by using SF, NS, and hydrated lime as improvers. The percent of asphaltene jumps from 15.59 to $22.46,21.62$, and 20.97 with adding $6 \%, 7 \%$, and $15 \%$ of SF, NS, and hydrated lime additives respectively to Amria low quality asphalt. Adding $12 \%$, and $9 \%$, and $15 \%$ of SF, NS, and hydrated lime additives respectively to Amria low quality asphalt reduce penetration to values lower than 70 units and getting asphalt totally acceptable to use safely in manufacturing stable hot asphalt concrete mixes.
\end{abstract}

Keywords: Low quality asphalt- Asphaltene- MaltenePenetration- Nano Silica (NS)- Silica Fume (SF) - Hydrated Lime.

\section{INTRODUCTION AND BACKGROUND:}

Freddy et al., (1) showed that asphalt cement is composed of asphaltenes and maltenes. Asphaltenes are precipitated when the asphalt cement is dissolved in a nonpolar solvent such as heptane whereas; maltenes is comprised of resins and oils. Asphaltenes play a major role as the viscositybuilding (bodying) component of asphalt cements. Studies have shown that the amounts and characteristics of asphaltenes vary considerably from asphalt to asphalt. Low asphaltene content (less than about 10 percent) or weakly associating asphaltenes have been linked with tenderness in hot mix asphalt by some researchers. Asphaltenes have three important functions: (a) it represents a bodying agent, (b) it forms a complex structure that aids in performance in conjunction with the other polar materials, and (c) it helps to reduce hardening with time. Tender mixes tend to rut easier and to be easily marred from power steering. If the aggregate gradation in the hot mix has too much sand, the mix will be very hard to compact. If the asphaltenes bodies up the mix well, compaction will go well even with over sanded mixes. Petersen (2) and Halstead (3) adapted the chemical composition of asphalt cement. The general elemental chemical compositions of asphalt cement are carbon, hydrogen, nitrogen, sulfur, oxygen, vanadium, and nickel. The relative percentage of each constitute in asphalt cement varies based on the origin of petroleum asphalt. The behavior of asphalt cement is greatly affected by its chemical composition. When the relationship between the polarasphaltenes is optimum, oxidation will be controlled. In the asphalt "micelles" $\{$ term coined by Petersen (2) $\}$, are formed such that oxidation is restricted for the material in the micelle so that the rate of oxidation decreases with time. With asphalts in which the asphaltenes are too well dissolved and micelles do not form, the rate of oxidation continues resulting in very hard asphalts in the pavement in a relatively short time. Original asphalt cement produced from refinery companies must be upgraded to meet special weather conditions through adjusting its original properties. Saleh, A.M.M (4) about the appropriate asphalt performance grade (PG) for Egypt, it was concluded that locally produced penetration graded asphalt $60 / 70$ must be modified using different methods of modification such as oxidation or polymer addition to produce the different appropriate required PG. It was found that the appropriate asphalt performance grade PG $64-10$ as well as are required for Delta zone. For western desert zone, PG 76-10 asphalt grade is the more appropriate asphalt performance grade. Original asphalt cement produced from refinery companies must be upgraded also in the cases asphalt has low asphaltene contents due to manufacturing problems. Many researchers $(5,6,7$, and 8) studied the effect of additives on asphalt properties. It was found that using silica fume, nano silica crumb rubber, limestone dust filler, and waste plastic bags as asphalt cement modifiers improved the bitumen properties. It decreases its penetration values and increases its viscosity. This paper aims to study the possibility of upgrading original Al Amria asphalt cement to meet the characteristics of 60-70 penetration grade asphalt cement. It discusses the effect of adding different percentages from silica fume, nano silica, and hydrated lime dust on percentage of asphaltenes and maltenes of the resulted upgraded asphalt cement as well as asphalt penetration values at all investigated study conditions.

\section{EXPERIMENTAL PROGRAM DESIGN:}

An extensive experimental program was designed to achieve the study objective. Flowchart describing experimental program is illustrated in Figure (1). The experimental program includes two stages; the first of them is a 
preliminary stage. It included the reviewing of all subjects and tests related to the study problem, followed by selecting the investigated materials as well as the evaluating tests. Stage 2 included the preparation of investigated samples according to different designed search conditions. Twenty samples of $100 \mathrm{gm}$ weight were prepared; the two of them where original Amria asphalt whereas, the reminder samples were Amria asphalt modified using different percentages of $\mathrm{SF}$, or NS, or hydrated lime. To prepare the investigated samples; a sample of about $2.0 \mathrm{~kg}$ of $\mathrm{Al}$ America original asphalt was heated in an oven of $150^{\circ} \mathrm{c}$ until it changed to liquid state. After that, the liquid asphalt sample is separated to

twenty separate samples of about 100 gm for each in a separate basin and then kept in the oven except two of them which were left directly in normal temperature room to represent the control sample of results which was used for comparison. A suitable weight of SF, NS, and hydrated lime were prepared in separate small containers. One of the eighteen asphalt sample kept in the oven was extracted and putted on a fire stove to keep its temperature constant during mixing process $6 \mathrm{gm}$ of SF (6\% SF by weight of sample) were weighted and thoroughly mixed with the asphalt sample using electric mixer shown in Figure (2) until reaching homogenous mixture of asphalt and SF, and then it was directly left in normal temperature room. Same procedure was used to prepare asphalt samples of 8 and $10 \%$ of SF. Also, same procedure was used to prepare asphalt samples of 7, 9, and $11 \%$ of NS as well as asphalt samples of 10,15 , and $20 \%$ of hydrated lime. Original asphalt sample, and all samples modified using SF, or NS, or hydrated lime were left at normal room temperature for at least $1.5 \mathrm{hr}$. before applying any evaluating test. The ten preprepared asphalt samples were then tested using penetration test during keeping all standard conditions of penetration test. Each sample was tested three times to find three penetration values of each specimen. Finally, all samples were taken to the Egyptian Petroleum Research Institute for making chemical analysis tests to find percentages of both asphaltene, and maltene for each sample. All results were collected and the required analysis was conducted to conclude the desirable ways to increase asphaltene percentage in Al Amria original asphalt and decrease its penetration to the acceptable range of 50-70 pen, grade.

\section{TESTED MATERIALS AND THEIR PROPERTIES:}

Al Amria asphalt cement was considered the original asphalt investigated for treating with different types of additives. The different characteristics of Al Amria asphalt cement is shown in Table (1). The table illustrate penetration, viscosity, softening point, flash point, $\%$ of asphaltene, $\%$ of maltene, as well as elemental analysis. Three types of additives were used to upgrade $\mathrm{Al}$ Amria asphalt cement; the first was SF. Micro-silica is a byproduct material produced by reduction of high-purity quartz with coal in electric furnaces in the production of silicon and ferrosilicon alloys. SF was obtained from Sika Company $1^{\text {st }}$ Industrial Zone (A)El Obour City-Cairo-Egypt. The physical composition of the used SF minerals is shown in Tables (2) and (3). The second type additives used to upgrade $\mathrm{Al}$ Amria asphalt cement was NS. NS used in this research was produced in Faculty of Science - Beni Suef University. The chemical composition of NS is presented in Table (4). Hydrated lime dust was the last type of additives used to upgrade Al Amria asphalt cement. Hydrated limestone dust filler was of bulk specific gravity of 2.750 and had gradation as shown in Table (5).

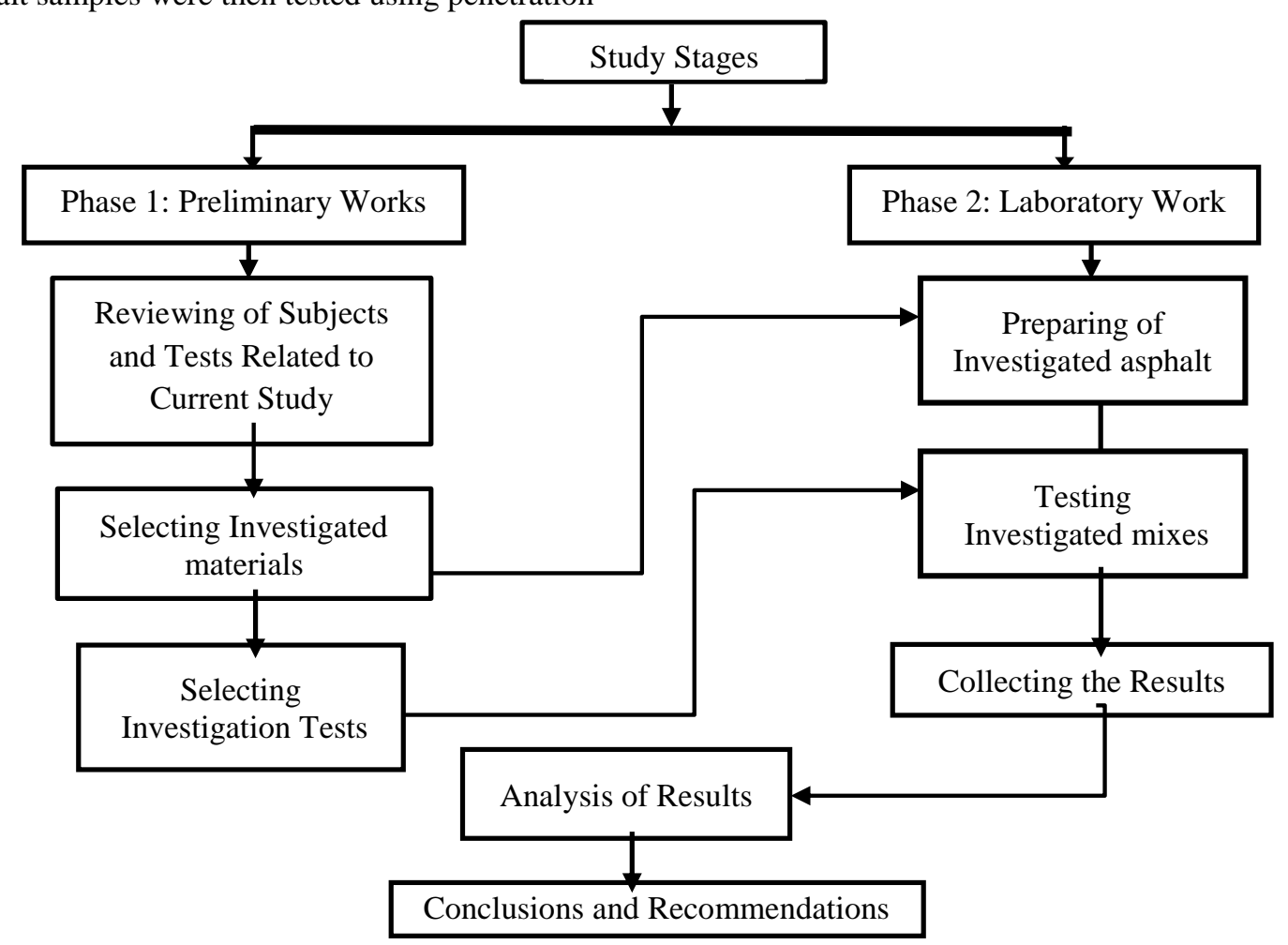

Figure (1): Study Methodology Flow Chart 
Figure (1): Study Methodology Flow Chart

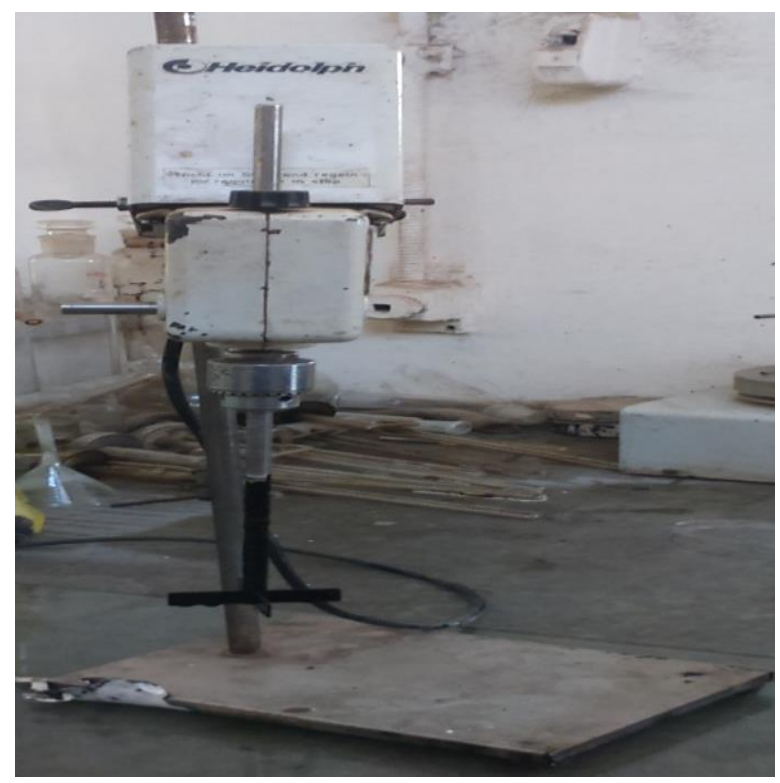

Figure (2): Electrical Mixer

Table (1): Different Characteristics of Al Amria Asphalt Cement

\begin{tabular}{|c|c|c|c|}
\hline Test & AASHTO Designation No. & Result & Specification Limits \\
\hline Penetration; 0.01mm & AASHTO T 49 & 96 & $60-70$ \\
\hline Kinematic viscosity; & AASHTO T 2O1 & 315 & $\geq 320$ \\
\hline Softening point; ${ }^{\circ}$ c & AASHTO T53 & 40 & $45-55$ \\
\hline Flash point; ${ }^{c}$ c & AASHTO T 48 & 225 & $\geq 250$ \\
\hline \% of asphaltene & $\begin{array}{c}\text { According to John H. and Nour elden, S. } \\
\text { (10, and 11) }\end{array}$ & 15.59 & ------ \\
\cline { 1 - 1 }$\%$ of maltene & & 83.74 & ------ \\
\hline
\end{tabular}

Table (2): Chemical Properties of SF ${ }^{[9]}$

\begin{tabular}{|c|l|c|}
\hline \multicolumn{1}{|c|}{ Parameters } & Test Value \\
\hline \multicolumn{2}{|c|}{ Chemical test } \\
\hline 1 & Silica as $\mathrm{SiO}_{2}, \%$ by mass & 89.90 \\
\hline 2 & Total ${\mathrm{Sulphur} \text { Content as } \mathrm{SO}_{3}, \% \text { by mass }}_{1}$ & 0.58 \\
\hline 3 & Lime as $\mathrm{CaO}, \%$ by mass & 7.85 \\
\hline 4 & Magnesia as $\mathrm{MgO}_{2} \%$ by mass & 4.03 \\
\hline 5 & Alumina as $\mathrm{AL}_{2} \mathrm{O}_{3}, \%$ by mass & Nil \\
\hline 6 & Iron Oxide as $\mathrm{Fe}_{2} \mathrm{O}_{3}, \%$ by mass & Nil \\
\hline
\end{tabular}

Table (3): Physical Properties of SF [9]

\begin{tabular}{|c|l|c|}
\hline No. & \multicolumn{1}{|c|}{ Parameters } & Test Value \\
\hline 1 & Density $\left(\mathrm{gm} / \mathrm{cm}^{3}\right)$ & 2.07 \\
\hline 2 & Physical state & Clear grey powder \\
\hline 3 & Practical Size Distribution, $(\%)$ & 59 \\
\hline 4 & Solubility & Solubility material \\
\hline
\end{tabular}


Table (4): Chemical Composition of NS

\begin{tabular}{|c|c|c|c|}
\hline Sample Name & SI & Anhydrite & 0.28 \\
\hline Date & $15-01-2019$ & Calcite & 0.25 \\
\hline Time & $20: 25: 22$ PM & Mulite & 0 \\
\hline R_wp & 5.52 & Magnetite & 0 \\
\hline Alite_Sum & 0 & Hematite & 0 \\
\hline Lime & 0.05 & Thenardite & 0 \\
\hline Periclase & 0.08 & Rutile & 0 \\
\hline Quartz & 0.20 & Si_amorph & 98.30 \\
\hline
\end{tabular}

Table (5): Gradation of Lime

\begin{tabular}{|l|c|c|c|}
\hline \multicolumn{2}{|c|}{ Type } & \multirow{2}{*}{$\%$ Passing } & \multirow{2}{*}{ Egyptian Limitation ${ }^{[10]}$} \\
\cline { 1 - 3 } Sieve Size (inch) & Sieve Size (mm) & & \\
\hline No.30 & 0.60 & 100 & $\geq 100$ \\
\hline No.50 & 0.30 & 100 & $\geq 85$ \\
\hline No.100 & 0.15 & 90 & $\geq 65$ \\
\hline No.200 & 0.075 & 75 & $\geq-$ \\
\hline
\end{tabular}

\section{RESULTS AND ANALYSIS:}

The results of chemical tests carried out at the Egyptian Petroleum Research Institute to Al Amria asphalt modified by different percentages of SF, hydrated lime, or NS are shown in Figures (3, 4, and 5). The figures illustrate asphaltene and maltene percentages of modified asphalt for various modifiers at different modifier percentages. The figures show that the percentages of both asphaltene and maltene of original Al Amria asphalt cement are 15.59, and 83.74 respectively. The figures also show that modifying $\mathrm{Al}$ Amria asphalt using various investigated modifiers increase asphaltene percentage and decrease maltene percentage. The maximum improving of asphaltene percentage in $\mathrm{Al}$ Amria asphalt cement is noticed for SF modifier as deduced from results comparison. Adding different percentages of SF to Al Amria asphalt cement increases asphaltene percentage from $15.59 \%$ to be in a range between 1.37 and 1.44 of its original value. Whereas it decreases maltene percentage from $83.74 \%$ to be in a range between 0.92 to 0.93 of its original value as shown in Figure (3). Using hydrated lime modifier achieves the minimum increasing of Al Amria asphalt asphaltene percentage and minimum decreasing in maltene percentage as shown in Figure (4). Different percentages of hydrated lime modifier increase its asphaltene percentage to values between 17.08 and 20.97. It also, decreases its maltene values to be in the range between 78.23 and 82.62. NS achieves satisfactory improvement in asphaltene and maltene percentages of Al Amria asphalt cement. Elemental analysis is performed to Al Amria asphalt cement after modification using SF, or NS, or hydrated lime is recommended to explain the reasons of increasing asphaltene and decreasing maltene percentages.

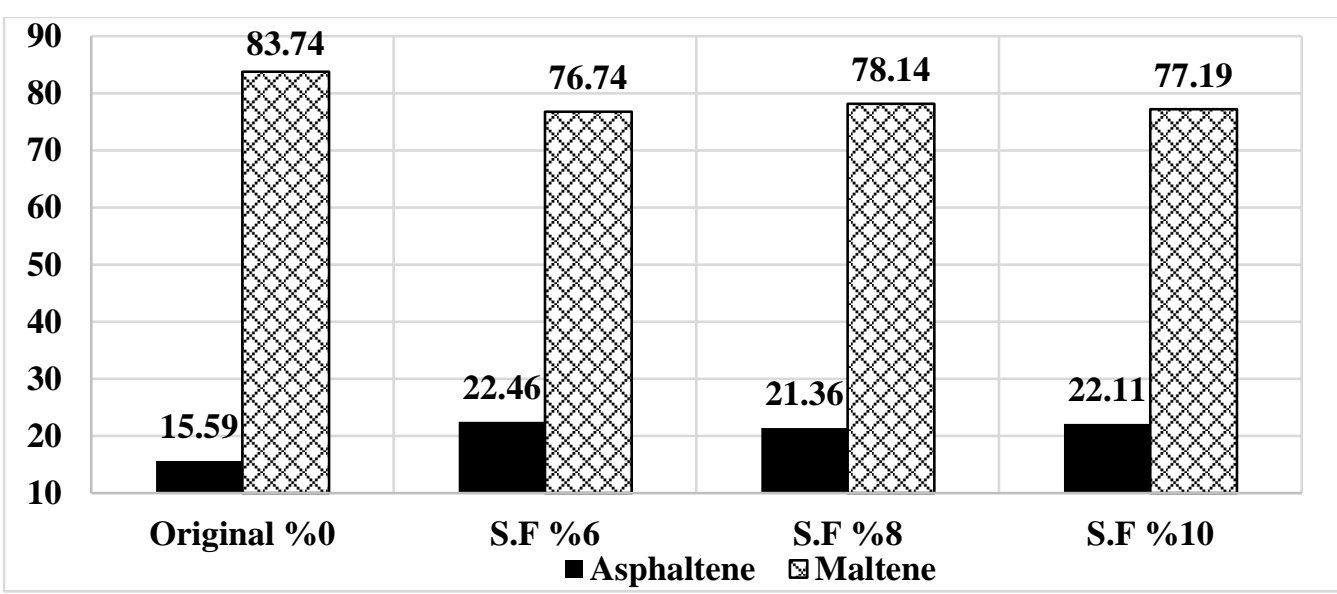

Figure (3): Percentages of Asphaltene and Maltene Contents of Al Amria asphalt cement at different percentages of SF modifier 


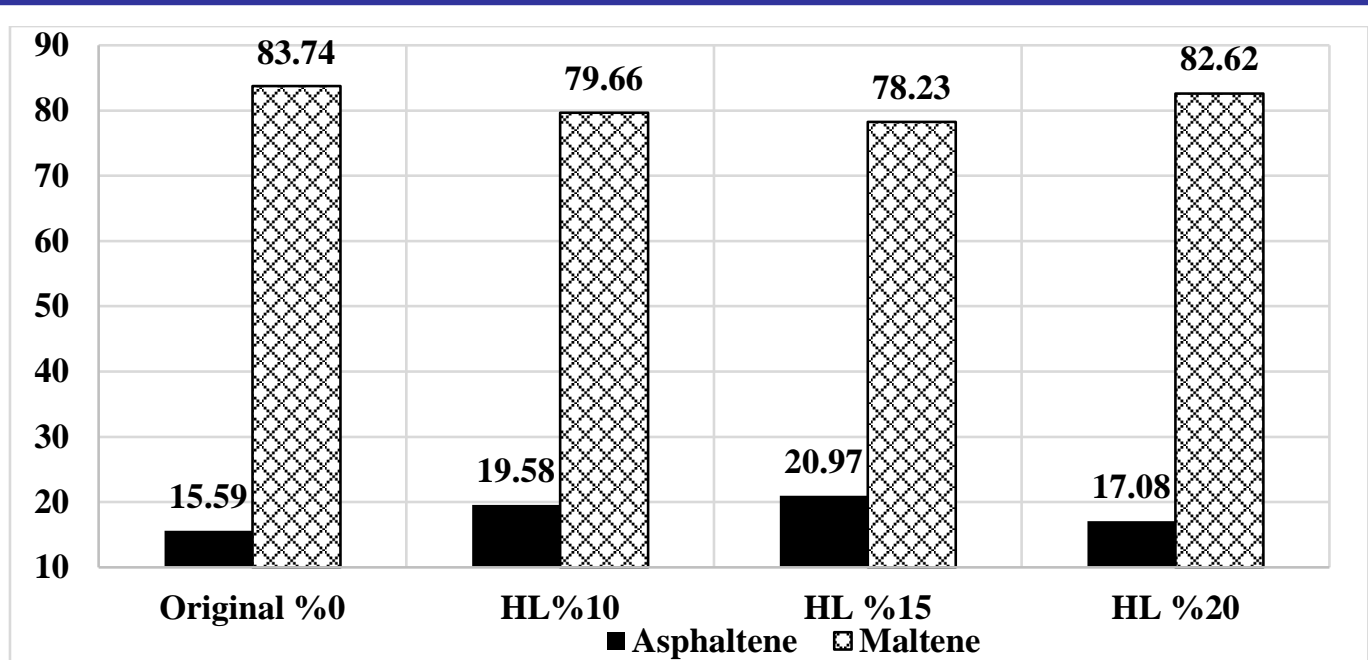

Figure (4): Percentages of Asphaltene and Maltene Contents of Al Amria Asphalt Cement at Different Percentages of Hydrated Lime Modifier

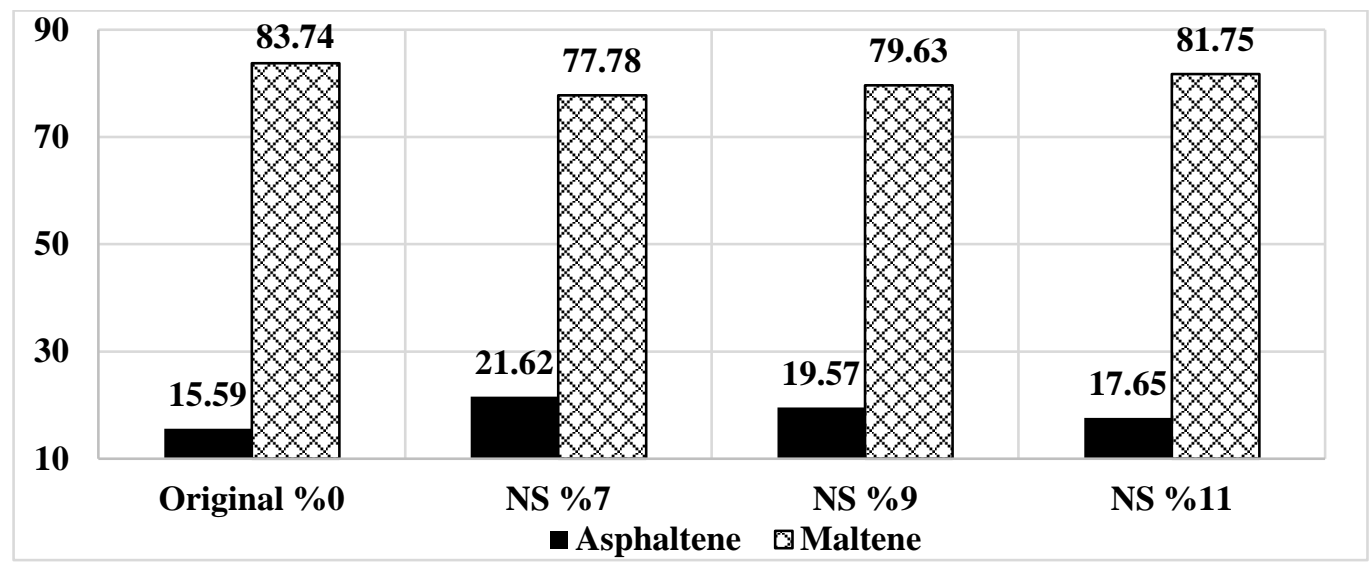

Figure (5): Percentages of Asphaltene and Maltene Contents of Al Amria Asphalt Cement at Different Percentages of NS Modifier

Figure (6) presents the effect of adding SF, or NS, or hydrated lime with different percentages on the penetration value of original Al Amria asphalt cement. The figure shows in general that as percentages of SF, NS, or hydrated lime increase the penetration value of $\mathrm{Al}$ Amria asphalt decreases. Strong relation between asphalt penetration and the percentages of SF or NS additive of about 0.92 , and 0.98 respectively as $\mathrm{R}^{2}$ was noticed. The decreasing of penetration of asphalt may be due to the decreasing of oil and increasing of asphaltene percentage in the original investigated asphalt. It can be concluded from analyzing data illustrated in Figure (6) that adding $12 \%$ SF, $9 \%$ NS, and 15 $\%$ of hydrated lime decrease penetration values of Al Amria asphalt cement to 70,66, and 67 units to meet AASHTO Specifications of 60-70 asphalt cement.

\section{CONCLUSIONS AND RECOMMENDATIONS:}

Analyzing study results, the following can be concluded:

1- In general, using Silica Fume (SF), Nano Silica (NS), and hydrated lime additives increase asphaltene percentages and decrease maltene percentages of $\mathrm{Al}$ Amria asphalt cement and decrease its penetration values.

2- Using SF additive as an improver to Al Amria asphalt cement achieves the maximum increasing of its asphaltene percentage. It increases its asphaltene percentage to values equaling (1.37 to 1.44$)$ of its original value.

3- Using hydrated lime additive as an improver to Al Amria asphalt cement achieves the minimum increasing of its asphaltene percentage. It increases its asphaltene percentage to values equaling 17.08 and 20.97 instead of 15.59 .

4- Al Amria asphalt cement needs to thoroughly mixing with $12 \% \mathrm{SF}$, or $9 \% \mathrm{NS}$, or $15 \%$ of hydrated lime, by its weight to produce asphalt cement meeting penetration AASHTO Specification.

5- Elemental analysis is recommended to perform to $\mathrm{Al}$ Amria asphalt cement after modifying it using $12 \%$ SF, or $9 \% \mathrm{NS}$, or $15 \%$ of hydrated lime to define the reasons of increasing asphaltene.

\section{REFERENCES:}

[1] Roberts,F.L., Kandhal, P.s., Brown, E.R., Lee, D.y and Kennedy, T.W, "HOT MIX ASPHALT MATERIALS, MIXTURE DESIGN AND CONSTRUCTION" National Asphalt Pavement Association Research and Education Foundation,, MD United States 20706-4413, (1996).

[2] Petersen, J Claine., "Chemical Composition of Asphalt as Related to Asphalt Durability", Transportation Research Board, Issue (999), 0361-1981, (1984).

[3] Halstead, W. J., "Relation of Asphalt Chemistry to Physical Properties and Specifications", Transportation Research Board, 1984 
[4] Saleh, A.M.M., and Trad, A.Metwally., "Generation of Asphalt performance Grading Map for Egypt Based on the Superpave Program", Construction and Building Materials, Volume (25), Issue (5), doi.org/10.1016/j.conbuildmat.2010.11.009, May (2011).

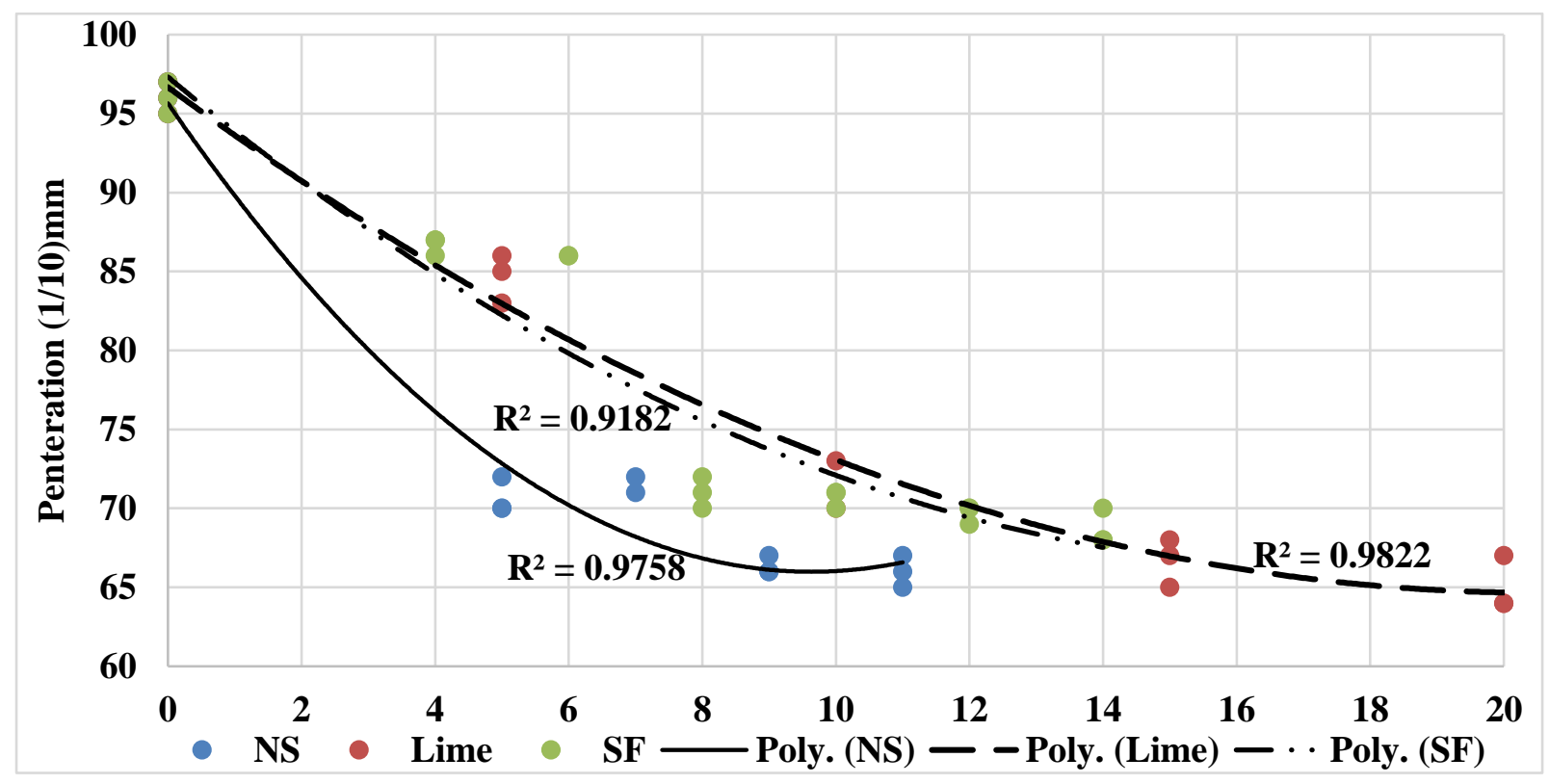

Figure (6): Penetration Values of Al Amria Asphalt Cement at Different Percentages of Hydrated Lime Modifier

[5] Al- Taher, M. G., Hassanin, H. D., Elgendy, M.F., and Sawan, A.M., "Improving the Performance of Asphalt Mixtures Using Nano Silica", World Applied Sciences Journal, Volume35, ISSN 1818-4952, December 2017.

[6] Al- Taher, M. G., Hassanin, H. D., Ibrahim, M.F., and Sawan, A.M., "Investigation of the Effect of Adding Silica Fume on the Asphalt Concrete Properties" Issue 4, ISSN 2319- 6890, April 2018.

[7] Al- Taher, M. G., Hassanin, H. D., Ibrahim, M.F., and Sawan, A.M., "Comparative Study of the Performance of the Modified asphalt Mixtures Using Different Traditional and Nano Additives", Journal of scientific and Engineering Research, Volume 9, Issue3, ISSN 2229-5518, March 2018.

[8] Abd-Allah, A.M., El-Sharkawi, M.I., Abd-Elmaksoud, M. F., and Deef Allah, E.M., construction Eng. And Utilities Dept., "Effecting of Using Polymers on Bituminous Mixtures Characteristics in Egypt", IOSR Journal of Mechanical and Civil Engineering, Vol.11, Issue 4, July-Aug 2014.

[9] Chhaya Negi, R.K.Yadav and A.K. Singhai. "Effect of Silica Fume on Engineering Properties of Black Cotton Soil", Geotechnical Engineering, JEC Jabalpur, (M.P.), India, International Journal of Computational Engineering Research, Vol, 03, July 2013.

[10] Egyptian Code of Practice for Rural and Urban Road Works, "Road Materials and Their tests", Code No. 104/2008, 4th Part, 1st Edition, In Arabic, 2008. 